\title{
41 AUTOMATED SYSTEM FOR LEATHER INSPECTION: THE MACHINE VISION
}

\author{
Mario Mollo Neto, \\ Oduvaldo Vendrametto, \\ Jóse Paulo Alves Fusco \\ UNIP mariomollo.cdg@unip.br, \\ UNIP vendrameto@unip.br. \\ UNIP jpafusco@uol.com.br. \\ BRAZIL
}

\begin{abstract}
Nowadays Brazil is the world largest producer of cattle leather and the total exportations in 2002 were around 19 million of pieces or 930 million dollars. In the other hand, the low performance of domestic tanning plants, has compromised the final numbers and as a result the product remains considered as a mere commodity in the international market. The semi-finished products obtained in the very first stages from the process, with low level of value aggregation, represent circa of $60 \%$ of exportations.

This paper is a summary of the findings obtained from a research done and aims to present an automated inspection system to classify the wet blue leather, using image processing and under a quality control system guiding rules.
\end{abstract}

\section{INTRODUCTION}

The globalization effects on developing (or emerging) countries has addressed the label of commodities exporters presented by them. The expectations of sharing the world market, commercializing products in higher levels of aggregated value, motivated by an increasing global competition, has occurred only in the importations side of the so called global products. The gap of knowledge presented by the Brazilian productive system concerning technology, management and quality, jointly with the MNC's tradition on international trading, weakened the position of national best firms. These ones, without conditions to face properly the fierce competition against their foreign counterparts, were incorporated by rivals or stopped operations or even reshaped their business anyway.

During the 90 's, because the adoption of partnerships, alliances, joint ventures or simply acquisition of Brazilian firms, the participation of foreign firms in the Brazilian GDP increases from 36\% (1991) to 53.5\% (1999) (Kupfer, 2002).

Changes on processes and operation systems, the use of automation technologies, TI, besides decreasing the participation of Brazilian investmens on the domestic market, co-operate to decrease the employement level and brought other types of 
social problems already on the table to be solved. While entire productive networks have been completely absorbed by foreign groups, e.g. autoparts and electrodomestics, conversely there are other remaining sectors virtually untouched as in the case of meat, leather and footwear, wooden-made furniture, gems and other. Probably some of typical characteristics presented by these sectors, e.g. labour intensive processes, lack of organizational control, lack of stable conditions concerning tax legislation and capital-labour relationships, and the general poor quality of buyer-supplier relationships, has pushed the focus of foreign investors away.

Some of the modern (regarded) firms evolved towards higher levels of competitive conditions, working concepts such as world products and making use of very sophisticated technologies and management tools. However, most of the remaining firms stay precariously in the business without investments in technology, and, therefore, in a low level of competitive power, still commercializing commodities or semi-finished products. Table 1 shows the potential of sales and development presented by the Brazilian network of meat, leather and shoes business. These numbers could be increased significantly through the adoption of an adequate set of policies by the federal government, aiming to increase the Brazilian share of international market and elevating the employement level as well.

Table 1 - Source: Couromoda Calçados e Artefatos $\quad$ (**) Additioned by the author

\begin{tabular}{|l|r|r|r|c|}
\hline \multicolumn{5}{|c|}{ Brazilian exportations of meat/leather/footwear - US\$ } \\
\hline \multicolumn{1}{|c|}{ Product } & $\mathbf{2 0 0 0}$ & $\mathbf{2 0 0 1}$ & $\mathbf{2 0 0 2}$ & $\begin{array}{c}\text { Variation \% } \\
\mathbf{2 0 0 0 / 2 0 0 2}\end{array}$ \\
\hline Shoes & $1,548 \mathrm{bi}$ & $1,615 \mathrm{bi}$ & $1,449 \mathrm{bi}$ & $-6,3$ \\
\hline Eláter & $744 \mathrm{mi}$ & $850 \mathrm{mi}$ & $930 \mathrm{mi}$ & $+25,0$ \\
\hline Components & $448 \mathrm{mi}$ & $500 \mathrm{mi}$ & \multicolumn{1}{c|}{$519 \mathrm{mi}$} & $+15,8$ \\
\hline Machinery & $5 \mathrm{mi}$ & $6 \mathrm{mi}$ & $\mathrm{ND}$ & $\mathrm{ND}$ \\
\hline Meat $\left(^{* *}\right)$ & $805 \mathrm{mi}$ & $807 \mathrm{mi}$ & \multicolumn{1}{c|}{$1,050 \mathrm{bi}$} & $+30,4$ \\
\hline \multicolumn{1}{|c|}{ Sum } & $\mathbf{3 , 5 5 0} \mathbf{~ b i}$ & $\mathbf{4 , 1 5 6} \mathbf{b i}$ & $\mathbf{2 , 9 4 8} \mathbf{b i}$ & $\sim+\mathbf{1 1 , 2}$ \\
\hline
\end{tabular}

The system proposed is based upon a type of "machine vision", to be developed using new technologies available, to perform activities within the process of classification of wet blue leather. Then, its main function would be to classify cattle leather just after the chemical treatment of tanning, looking for increasings on quality standards.

The classification occurs after the very first stage of the production process, on the semi-finished product called wet blue. One piece at a time is then extended over one special table and one specialist takes a visual inspection on the leather surface for around 30 and 60 seconds. The specialist then evaluates the quality and assigns the piece a grade between 1 and 7, writing it with a chalk on its surface. According this scale, one piece of leather graded 1 would present the best "value" for quality while the other limit would refer to the worse quality.

The procedure cited above is quite arguable because of its large uncertainty margin and this fact represents the main reason behind the existing commercial problems between tanning plants and their customers, primarily in the case of exportations. 
The resulting pieces of leather can be commercialized in a briny or crude state, without being submitted to any inspection of quality up to this phase. Only after the process on tanning plants the piece is converted into leather one and classified, receiving the grade. This late evaluation can bring losses to the tanning plants, because the quality will be known only in the end of the entire production process.

Additionally, the "machine vision" presented and proposed in this paper will help firms to know precisely what they are really doing in terms of quality of good products, creating a value basis to support commercial negotiations in a more realistic way, instead of making use of speculative arguments as up to now.

The new form proposed intends to analyze electronically the leather through the use of one digital optical system, mapping the defects on each piece and obtaining the correspondent classification or grade. Besides, the leather mapping allows the application of more specialized methods to optimize the working area on it, decreasing rejects and the related environmental problems.

One experimental test was done to verify the compatibility of the system proposed and the present visual system in terms of the outputs and the quality of the data to be generated. Despite the fact that the technology proposed still needs a more profound examination before its full adoption by firms, the results suggest that both systems are totally compatible.

\section{BACKGROUNDS}

Along the last 30 years the research field called "machine vision" has been evolving and developing to play an important role on either side of production processes (using robotics) and quality control of manufacturing operations (AVI - AudioVideo-Interleaved systems).

In the early papers, the main purpose has been to automate the quality control through the use of images (Stapley, 1965; Norton, 1970; Aalderink, 1976; Saridis, 1976; Roland, 1982).

Many researches have been conducted in the last few years to elaborate high speed techniques more efficient to analyze images, trying to emulate the human vision. To do so, besides the images processing system, it is necessary to develop another technique of decision making, very difficult to automate indeed.

In parallel with the academic evolution, the required technology to capture images (e.g. cameras, digitizers) and their subsequent treatment (computers, microprocessors) has been developed in such a way that nowadays it is possible to build a sort of very efficient visual systems to capture images and to take decisions based on information gathered from it.

The development of a system to a nalyze quality u sing i mage p rocessing involves many other important aspects from the choice and implementation of adequate methods up to the elaboration of experiments to verify its suitability.

\subsection{Scenario analysis}

The research focusing leather issues has been done under a wider range, going beyond the usual activities involving its simple applications as a part of other products or even as a supply in the leather artisan industry. 
The innovations already cited in the text revealed new horizons to the leather sector and d eserve to receive special a ttention b ecause the possibility to obtain p roducts with more aggregate value, competitive advantages and increasings on ROI.

Nowadays the leather, as a raw material, is responsible for an important economic sector w orldwide, presented a great diversity of products from $m$ anufacturing and service firms. Porter $(1993,479-497)$ presents the competitive advantages that lead Italy into the world leadership of leather industry. Soon after, the author suggested in a lecture the figure 1 a bove, containing one wide $v$ iew of the different sectors forming the entire network.

Concerning cattle leather, results obtained from many researches revealed that Brazil has missed an opportunity to gain close to 900 million dollars each year because the poor quality of the leather produced by domestic plants and the unbalance between domestic production and demand (CICB, Brazilian leather plants union, 2000). Usually pieces of leather used as raw materials by manufacturing firms (footwear, purse, belt, Clothes, furniture and car seats) present scratches, scars, punctures and spots over their surfaces.

It is important to point out that $85 \%$ of the leather made in Brazil presents some type of defects, and $60 \%$ of that occurs within the limits of the tanning plants. The remaining $40 \%$ occurs because the bad conditions of logistic factors from the farms to the plants.

a) Figure 2 shows the types of defects presented by the leather made in Brazil. The general lack of secure information about the leather as a product, inside the limits of the farms, represent a huge difficult to be overcome.

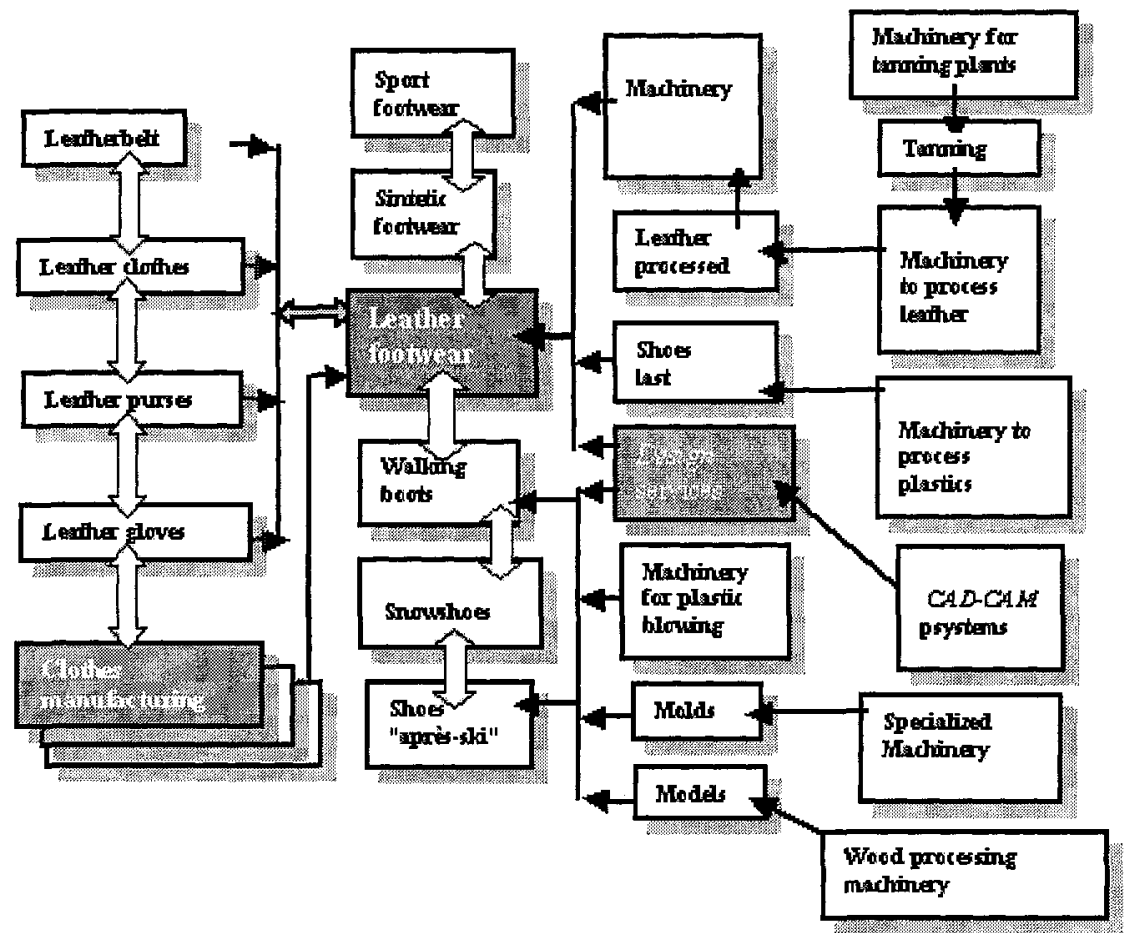

Figure 1 - One Italian footwear cluster - Source: Porter, 1997 


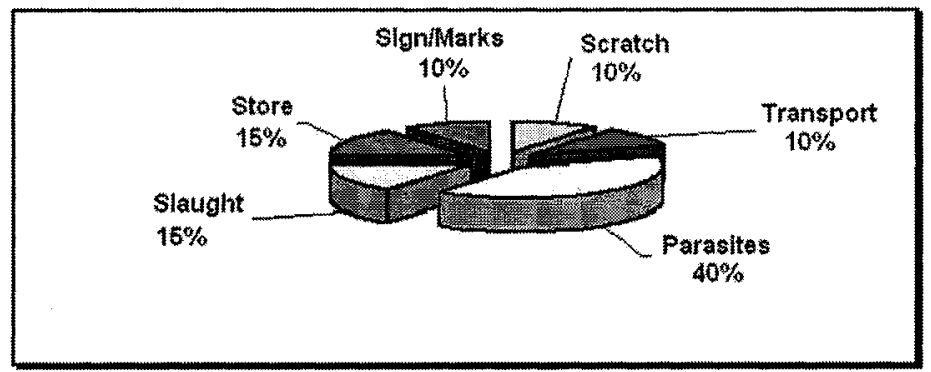

Figure 2 - Defects of Brazilian leather - Source: ABQTIC (1998)

Additionally, three relevant questions need to be considered:

b) The geographic localization and climate conditions of the country, with some regions quite suitable to microbe proliferation and also the emergence of a wide variety of coetaneous diseases. All this stuff requires additional efforts during the entire productive process to obtain the leather.

c) The present practices adopted by the slaughtering plants require corrective actions to i mprove the product to be sent to the tanning plants, a voiding undesiring rests, usually accepted because of sales criteria (weight).

The treatment process of effluents released by the plants need to be developed more properly to eliminate environmental impacts.

In fact there is a negative cycle to disrupt. The poor profitability presented by the leather sector raises difficulties to answer the question of poor quality. To do so it becomes necessary to provide an adequate flow of investments on new technologies, innovation, management and negotiation processes involving suppliers and customers together. The need of further developments on products and manufacturing plants is quite evident indeed. Efforts in such a way would bring significant results to every firm within the business network, and would increase the incomes from Brazilian exportations.

In so far as the wider and deeper relationships between agriculture sector and other sectors, upright and downright within the productive chain, its connection with other economic segments has been expanded as well. Thus, any macroeconomic or sectorial change affecting one or more structural link of the CAI (Agro industrial Complex) also reverberates on the national economic structure.

Impacts on other sectors would induce side-effects on the Agro industrial Productive Chains (CPA-A groindustrial Productive Chain). The participation of agribusiness incomes represents something around one third (1/3) of Brazilian GDP (Gross Domestic Product), also a large number of people employed and close to $34,5 \%$ of total of domestic sales (Embrapa-gado de corte, 2001).

Although Brazil experiments presently an accelerated process of economic internationalization, the solely economic globalization tends to induce changes on every economic and political aspects of the country. In fact, it is quite difficult to isolate economic events to avoid the natural implications on political and social aspects. To sum up, all of this make necessary to think again about the participation of the federal government in such scenario without one defined array of rules.

It becomes important to point out that, under a type of "free trade" criteria, and in a global sense, one can list three main characteristics to be included as a part of an essential strategic agenda: Organization, representativity and power to negotiate. 


\subsection{Why to invest on technology?}

\subsubsection{Economic point of view}

The leather and footwear sector is extremely important concerning Brazilian economy, because its volume of exportations and generation of jobs. The country presents the largest commercial herd of the world and also one of the largest groups of cattle breeders, slaughtering and tanning plants. According to information gathered from the Brazilian agriculture office, the industry generates close to $2 \%$ of GDP(Gross Domestic Product) and around of 800,000 direct and indirect jobs. (Gostinski, 1997)

Because the high rate of defects and the general lack of uniform batches, the Brazilian tanning plants (per year) embitter a loss of incomes around 320 million dollars. The state of Rio Grande do Sul, responsible for $40 \%$ of the total leather manufactured in the country, shows close to 128 million dollars of unrealized sales per year. Regarding the farmers and slaughtering plants, it represents a loss of incomes of 270 million dollars per year. In the same reasoning, the state government suffers a loss of taxes close to 12 million dollars per year.

Thus, it becomes clear that every investment made on technology development would probably bring significant results and increasing on profitability of the firms within the business network.

\subsubsection{Manufacturing point of view}

The scope of the research presented in this paper encompasses areas of equipments and technologies adopted by the tanning plants (figure 3 ).

The technology proposed within the "machine vision" needs to be incorporated as another equipment to classify properly (capable of being reproduced) and economically the pieces of leather and aggregating value to the entire process. This type of automation would generate improvements on quality and efficiency, without being dependent on foreign technologies. It could also settle the economic profile of the tanning plants because the optimization of raw material and labour.

\section{THE AUTOMATED CLASSIFICATION SYSTEM}

\subsection{System design}

The classification is based upon the determination and mapping of defects presented in the surface of the leather motivated by external agents. Nowadays, the classification is totally performed visually, being highly dependent on the operator's ability, therefore imprecise and subjective (Oscar, 1988). The proposed system divides the batches of leather according 8 standard levels of classification commonly used in the market.

The proposition aims to automate the process through the adoption of a computerized classification, more reliable and capable of being reproduced. The software "embedded" within the machine analyze digitally images obtained from a piece of cattle leather and store it in a data bank with other information about non- 
conformities or defects such as total area of defects, eccentricity, optical density, and defects per unit (piece of leather). Thus, the information stored would allow firms to compare the results obtained from each inspection against the quality standards accepted in the market.

In general terms, the machine gets the images from a piece of leather using one or more CCD (Charge-Coupled Device) cameras, digitally converted by a microcomputer (PC-like), using a video converter device. The proposed "machine vision" is a composite of one hardware set and another of control software (Roland, 1982) to perform the following functions (see figure 3):

a) Establish the real dimension of the piece to be analyzed

b) Establish the useful area to be used by subsequent processes

c) Track the defects and the influences over the piece under analysis

d) Calculate the total weight of the defects presented by the piece and determine its batch classification

e) Storage of the information gathered from the individual and batches analysis

f) Generate reports containing defects and non-conformities found in each piece or batch of leather

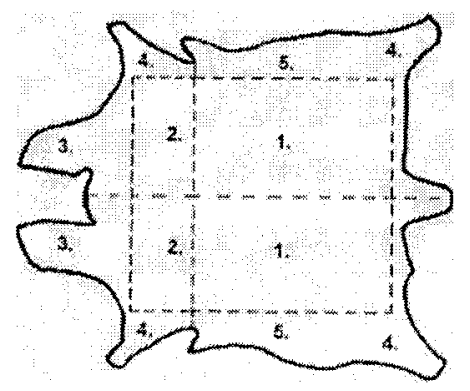

1. Rear, know as "Grupon".

2. Shoulder.

3. Head I neck.

4. Claw

5. Belly

Figure 3 - Source: SENAI tanning school $-2^{\circ}$ grau, april, 1988 (Oscar Jacó Schefel and Valmar Silveira dos Santos, quality control of Wet Blue and semi-finished leather).

\subsection{Physical assembly}

The physical application requires the use of a special table to receive the pieces to be surveyed (see figure 4) with a translucent lid to back-of illumination and with an attached metallic structure to install one fixed camera to be used in the analysis to get the quality of the "grupon"(Best part of one piece of leather) and other regions. The data generated are then processed by the software and compared against a data bank, in such a way to understand the meaning of the data and related evaluation.

\subsection{Measurement process}

As already cited within the text, the implementation of an accessible and low cost automatic system to control the quality of leather still remains as an important objective to reach. 


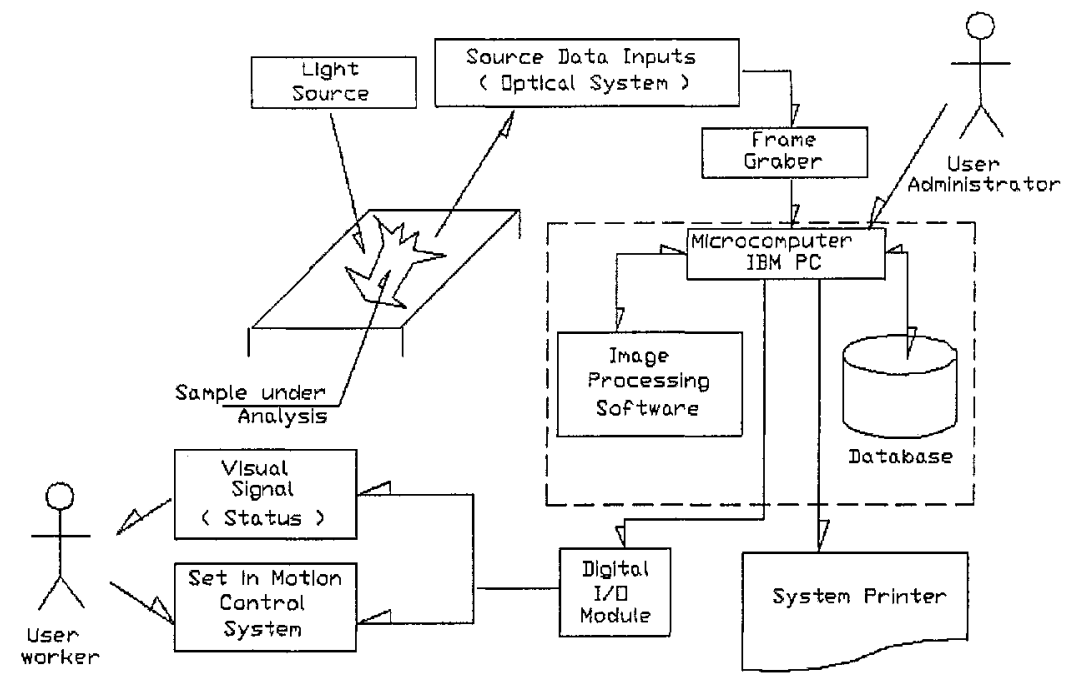

Figure 4 - Automate inspection process of quality leather

To sum up, the process comprises the following activities:

a) Capture images digitally generated by the cameras

b) Put to use one specialist system of visual computation to detect variations on leather characteristics in comparison with standards

c) Link the system above mentioned with the operator through the use of reports, warning or whatever considered more convenient

\subsection{Benefits and costs}

The proposed system would be able to eliminate or reduce the uncertainty level of the present hand-made classification process, aggregating value to the products being obtained and pushing the pricing negotiations into higher levels.

This system-based process allows more favorable conditions to conduct studies about leather quality, because the availability of data and information about the types and localization of defects found in each batch, species and region. In having plenty of information it becomes possible to implement special policies to decrease the problems of quality through the elimination of the reasons behind them.

\section{A PRELIMINARY TEST}

The proposed system has been tested in a leather tanning plant located in Franca, one of the Brazilian footwear cluster, The table 2 presented below shows the results obtained from one preliminary test, involving the inspection and classification of a sample with 20 pieces of leather. To do so, one experimental test has been done to classify the sample using two methods, e.g. one using visual classification and the other performed automatically by the system. 
After the tanning process, the piece of leather is then divided in two longitudinal halves, from the neck to the tail of the animal. These parts received an identification tag (R-right; L-left side) represented in the third column of the table.

Table 2 - Results obtained for the experiment

$\begin{array}{cccccccc}\text { Sample } & \text { Results } & \text { Orient. } & \text { Average } & \text { Sample } & \text { Results } & \text { Orient. } & \text { Average } \\ \text { 1P4 } & 2338,14 & \text { L } & 1902,10 & \text { 3P6 } & 3099,61 & \text { L } & \\ \text { 2P4 } & 1922,12 & \text { L } & & 4 P 6 & 2905,82 & \text { L } & \\ \text { 3P4 } & 1584,03 & \text { R } & & 1 P 7 & 4770,02 & \text { R } & 5485,41 \\ \text { 4P4 } & 1764,13 & \text { R } & & 2 P 7 & 5864,31 & \text { R } & \\ \text { 1P5 } & 2394,97 & \text { L } & 2482,41 & 3 P 7 & 5613,64 & \text { L } & \\ \text { 2P5 } & 2673,06 & \text { L } & & 4 P 7 & 5693,69 & \text { L } & \\ \text { 3P5 } & 2348,67 & \text { L } & & \text { 1PR } & 7901,23 & \text { R } & 7846,46 \\ \text { 4P5 } & 2512,97 & \text { L } & & \text { 2PR } & 7865,42 & \text { L } & \\ \text { 1P6 } & 2976,39 & \text { L } & 3092,76 & \text { 3PR } & 7657,94 & \text { R } & \\ \text { 2P6 } & 3389,25 & \text { R } & & \text { 4PR } & 7961,27 & \text { R } & \end{array}$

The first column represents the elements of the sample under test, while the second shows the results obtained to each element, through the application of factors pondering the types of defects, their location over the surface and the density of the piece. According the table, the results increase according a logarithmic curve, determining like bands of value to define each level for classification (grade). To check the methods against each other, the sample was divided in five groups according levels of grade well known previously. Thus, the sample presented 4 pieces grade 4, 4 pieces grade 5, 4 pieces grade 6,4 pieces grade 7 and 4 pieces to be rejected.

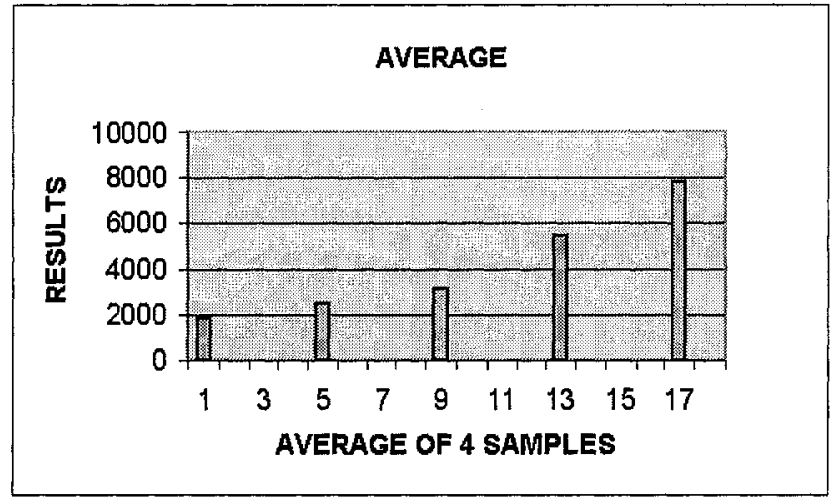

Figure 6-Compatibility of the methods

After all, the last column represents the average value obtained for the testing results of each group of pieces.

The cycle time to classify and to measure each piece by 1 operator and 4 assistants $h$ as been taken close to 43 seconds. To do the same job, in the present stage of development, the automate system lasts around 53 seconds to classify and measure by using of electronic processing devices. However, it is important to take in account that the equipment used to do the experiment was one personal laptop 
without any special feature to enhance its performance. Thus, it is reasonable to say that using another computer system with high performance should reduce to an estimate value of 30 seconds, suitable to this type of activity.

\section{CONCLUSION}

As a conclusion from the reasons and the preliminary test presented in this paper, there are many related elements that could justify the adoption of one or more units of the "machine vision" to improve quality of wet blue leather produced by the tanning plants, aggregating value to the products been sold in the domestic and foreign markets.

Another important gain refers to the development itself and the knowledge of a new technology like that, adjusted to the economic capacity of Brazilian firms. There are many other possibilities available in the market to perform such a task, however the prices are still too much expensive, besides the fact that usually it generates a type of technologic dependence in terms of adopting one unique machine and its maintenance. Therefore, with the knowledge and range to specify the types of defects presented by the leather, besides one more detailed cost-benefit analysis and study to fulfill the needs to design and produce a "machine vision", it becomes possible to obtain a more uniform classification of leather being produced by tanning plants and increasing the quality level of the material to be used downright by other firms within the productive chains.

\section{REFERENCES}

1. Aalderink,B.J. and deJonge, M.W.C. (1976) Automated Surface Inspection of cold-rolled sheet In Proc. International Meeting of Iron and Steel Making, pp 11-19.

2. AVA (1985) Machine Vision Glossary, Automated Vision Association.

3. ABQTIC (1988) Matéria-prima couro. Estância Velha.

4. COUROBUSINESS (2000) Para onde vai o couro brasileiro. vol. 3, n. 13, p.20-21.

5. Embrapa - Gado de Corte-MS (2001) Sistemas integrados de produção de peles e couros no Brasil. Novembro.

6. Gostinski C. (1997) Brasilian footwear 96/97. English/Portuguese. Novo Amburgo: Catânia.

7. Norton-Wayne, L. and Hill, W.J. (1970) The Automated Classification of Defects on Moving Surfaces Second International Joint Conference on Patt. Recognition, pp 476-478.

8. VENDRAMETTO, O. ; Desenvolvimento e Ruptura: O caso da rede produtiva da carne, couro e calçados. In : FUSCO, J.P.A. (Organizador): Tópicos emergentes em engenharia de produção. Vol.01, São Paulo, Arte e Ciência Editora, 2002, ISBN 85-7473-091-2.

9. Oscar J. S.; dos Santos, V. S. (1988) Controle de qualidade de couros "Wet Blue" e semiacabados. Escola de curtimento SENAI $-2^{\circ}$ grau, abril.

10. Porter, M. (1993) A vantagem competitiva das nações. RJ: Editora Campus. Pp 479-497.

11. Revista Globo Rural (1987), junho.

12. Roland T. C.; Harlow, C. A. (1982) Automated Visual Inspection: A Survey IEEE Transactions on Pattern Analysis and Machine Intelligence, vol. PAMI-4, No 6, pp 557-573, November.

13. Saridis, G.N. and Brandin, D.M. (1979) An Automatic Surface Inspection System for Flat Rolled Steel. Automatica, vol. 15, pp 505-520.

14. Stapley, B.E. (1965) Automatic Inspection of Metal Visible Defects. Iron and Steel Engineer, november. 